\section{Design Thinking para educadores: uma aplicação em videoaulas. Design Thinking for educators: an application in video lesson.}

Paulo Vitor Tavares, Ms, UFSC, Brazil < tavarespv@hotmail.com >; Luciane Maria Fadel, PhD, UFSC, Brazil < liefadel@gmail.com >; Gisele Baumgarten Rosumek, UFSC, Brazil < gisele.baumgarten@gmail.com >; Richard Perassi Luiz de Sousa, Dr, UFSC, Brazil < richard.perassi@uol.com.br >; Francisco Antonio Pereira Fialho, Dr, UFSC, Brazil < fapfialho@gmail.com >.

Palavras-chave: Design Thinking, Educação, Videoaula.

Resumo: Este artigo analisa, o processo empírico utilizado na produção de um conjunto de videoaulas. Esse processo de produção de videoaulas é centrado no aluno como produtor. O método empregado para essa análise é o Design Thinking sendo que o processo foi analisado a partir de suas cinco etapas. Como resultado foi possível identificar claramente ações relacionadas às etapas Descoberta, Interpretação, Experimentação e Evolução do método, o que sugere que é possível aplicá-lo por completo, e com isso potencializar uma prática educativa baseada na resolução de problemas e na colaboração, incentivando o aluno a vivenciar o próprio processo de construção do conhecimento.

Key-words: Design Thinking, Education, Video Lessons.

\begin{abstract}
This paper analyses the empiric process used in the production of a range of video lectures. This production process is centred on the student as the producer. The method applied for the analysis is the Design Thinking, and the process was analysed considering its five stages. The results suggest that is possible to identify actions that are related to all phases but Ideation. Using Design Thinking could highlight the education practice based on problem resolution and collaboration, which can motivate the student to experience his own process of knowledge construction.
\end{abstract}

\section{Introdução}

A escola passa por um momento de crise em decorrência de se apresentar pouco interessante no sentido de envolver o aluno. Além disso, um novo padrão de sociedade vem se configurando e, segundo Martins Filho, Gerge e Fialho (2015, p.581), isso "requer diferentes habilidades, competências e atitudes". Para os autores este padrão deve ser percebido pelos gestores educacionais e professores quando lidam com seus discentes nos dias atuais, pois há um "distanciamento abissal entre a maneira de raciocínio dos indivíduos considerados imigrantes digitais e os considerados nativos digitais" (MARTINS FILHO, GERGE E FIALHO, 2015, p.582).

Dentro deste novo cenário, Zabala (1998) considera que há a necessidade de desenvolver situações em que os alunos possam participar ativamente na resolução de problemas relacionados aos seus campos de estudo. Com essa perspectiva Yarzábal (2002, apud MARTINS FILHO, GERGE E FIALHO, 2015) reflete que, atualmente, o conhecimento passa a ser interdisciplinar ao invés de monodisciplinar, isto é, deixa de estar centrado na disciplina para estar centrado em um problema. Martins Filho, Gerge e Fialho (2015) consideram a aplicação do Design Thinking como uma possibilidade de realizar a

Anais do 8 ${ }^{\circ I D I ~ e ~ 8 ~ C O N G I C ~}$

Guilherme Santa Rosa; Cristina Portugal (orgs.)

Sociedade Brasileira de Design da Informação - SBDI

Natal | Brasil | 2017

ISBN 978-85-212-1305-5
Proceedings of the $8^{\text {th }}$ CIDI and $8^{\text {th }}$ CONGIC Guilherme Santa Rosa; Cristina Portugal (orgs.) Sociedade Brasileira de Design da Informação - SBDI Natal| Brazil | 2017

ISBN 978-85-212-1305-5 
migração dessa prática centrada na disciplina para um conhecimento estruturado em problemas.

Considerando esse contexto, o artigo analisa o processo empírico utilizado na produção de um conjunto de videoaulas para a disciplina de Radiobiologia do Curso de Radiologia do IFSC considerando-se a abordagem do Design Thinking para Educadores (IDEO; RIVERDALE, 2013). A análise foi realizada após a produção dos vídeos (objeto de pesquisa), usando como fontes de informação: registros de e-mail trocados entre os professores envolvidos; memorandos enviados ao departamento TV IFSC na época de execução do caso estudado; arquivos de vídeo de making of e resultado final disponíveis no departamento de TV do IFSC.

\section{Fundamentos de Design Thinking}

Design Thinking é, resumidamente, a aplicação do pensamento dos designers para solucionar qualquer tipo de problema. Brown (2010) defende que o método já aplicado e validado pelos designers seja usado em diversas outras áreas de negócio, buscando colocar à disposição ferramentas de design "nas mãos de pessoas que talvez nunca tenham pensado em si mesmas como designers" (BROWN, 2010, p. 3), aplicando, assim, o pensamento de design a uma grande diversidade de problemas. Vianna et. al. (2012) consideram o Design Thinking como um processo que visa à resolução de problemas complexos, de forma colaborativa e centrado no ser humano.

A formação da equipe é ponto fundamental para facilitar a colaboração. A complexidade da maioria dos problemas, conforme pensamento já citado de Vianna et al (2012), exige que eles sejam resolvidos em equipe. Preferencialmente que esta equipe seja interdisciplinar, com pessoas de diferentes perfis e área de atuação, e que sejam do tipo T, nomenclatura dada por Brown (2010) a pessoas que possuem competências em profundidade para contribuir com o problema ao mesmo tempo da capacidade para colaborar nas outras diferentes disciplinas envolvidas.

Outro ponto a ser observado é que as equipes sejam preferencialmente pequenas, evitando o "pensamento grupal", que cria uma ilusão de unanimidade artificial (ROBBINS, 2009).

Brown (2010), Martin (2010) e Vianna et al (2012) consideram que o Design Thinking envolve uma alternância entre modos de pensamento, ou estados mentais, chamados de pensamento convergente e divergente. O pensamento Convergente é o pensamento lógico e racional. Já o Divergente é o pensamento considerado criativo.

Do decorrer do processo de Design Thinking podem ser observadas algumas etapas. Martin (2010, p.117) as resume em: "trabalhar iterativamente, construir um protótipo, obter feedback, aperfeiçoar o protótipo e repetir o processo". Brown (2010) descreve o que ele considera os três espaços para a inovação: a Inspiração, onde se coleta todo tipo de informação; a Idealização, em que se busca conexões entre estas informações gerando novas ideias; e a Implementação, no qual as ideias geradas são aplicadas.

Os autores concordam com o briefing como ponto de partida para o processo, contendo a definição do problema e as primeiras informações sobre ele, sem ser nem muito aberto nem muito restritivo.

Após o briefing com a definição do problema, inicia-se a etapa de Inspiração. Brown (2010) sugere que nessa etapa seja pesquisado o comportamento das pessoas, inclusive as que se caracterizam como usuários extremos, diferentes do padrão tradicional.

Após mergulhar no problema de forma intensiva na etapa de inspiração, segue-se a etapa de idealização. Brown (2010), Vianna et. al. (2012) e Ambrose e Harris (2011) apresentam diversas técnicas e ferramentas que auxiliam nesta etapa, como o Brainstorming e o Pensamento Visual. 


\section{CIDI 2017 告 cold

O Brainstorming - tempestade de ideias, consiste em reunir um grupo de pessoas para gerar a maior quantidade possível de ideias para solucionar um problema em conjunto, tirando partido de características como o pensamento divergente e o pensamento associativo coletivo (AYAN, 2004). Já o Pensamento Visual recorre a, por exemplo, desenhos como forma de expressar ideias e forçar a tomada de decisão (BROWN, 2010).

Como ponte entre a Idealização e a Implementação utiliza-se como ferramenta a Prototipagem, que consiste em dar uma forma tangível à ideia, oferecendo uma oportunidade de testá-la de diferentes maneiras para avaliar sua possibilidade de sucesso na prática (AMBROSE E HARRIS, 2011).

Entre os recursos de prototipagem citados pelos autores Brown (2010), Vianna et al (2012) e Ambrose e Harris (2011) destacam-se: (a) Storytelling: criar histórias, narrativas, que contextualizem e deem significado à ideia. (b) Storyboard: sequência de imagens ou desenhos em quadros, com ou sem blocos de texto, representando a experiência no uso da ideia. (c) Dramatização: também chamada encenação ou role-play, envolve a representação de papéis, de forma ensaiada ou improvisada. (d) Diagrama: desenho de mapas, fluxogramas de processo ou linhas do tempo. (e) Jornada do Cliente: mapeamento dos pontos de contato onde ocorre interação entre o cliente e o serviço ou marca. (f) Maquetes: representação tridimensional. (g) Material digital: produção de fotografias, vídeo ou áudio. (h) Virtual: utilização de 'mundos virtuais' ou redes sociais para testar as ideias e obter feedback.

\section{Análise da produção colaborativa de videoaula}

Originalmente desenvolvido pela IDEO em 2012 em parceria com o colégio americano Riverdale, e adaptado para o Brasil em 2013 pelo Instituto Educadigital, o livro Design Thinking para Educadores (IDEO; RIVERDALE, 2013) buscou adequar a abordagem do Design Thinking aos desafios cotidianos que os educadores enfrentam. Esta adaptação pela IDEO propõe que a etapa de Inspiração é desdobrada em Descoberta e Interpretação; a etapa de Idealização é renomeada como Ideação e destaca em separado a Experimentação (prototipagem); e a etapa de Implementação é rebatizada de Evolução; conforme demonstra a Figura 1.

Figura 1: fases do processo Design Thinking. Fonte: dos autores com base em http://www.dtparaeducadores.org.br/site/oque-e-design-thinking/

Fases no Modelo IDEO - DT para Educadores:

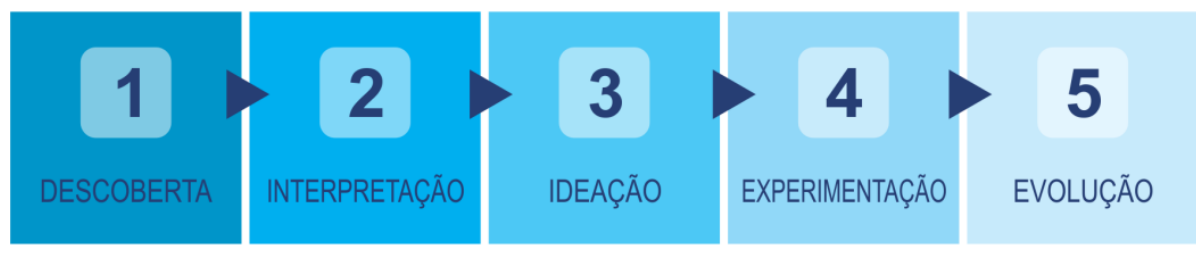

Fases no Modelo de Tim Brown:

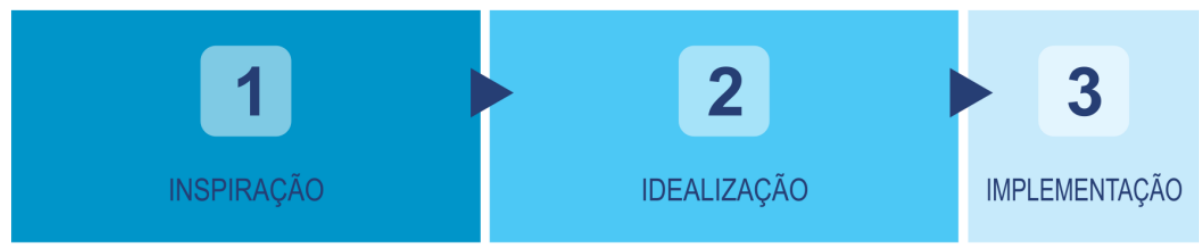

O e-book Design Thinking para Educadores (IDEO; RIVERDALE, 2013) exemplifica a aplicação do método por professores da Ormondale Elementary School, na Califórnia, 
chegando ao que chamam de "aprendizagem investigativa", que trata os alunos não como receptores da informação, mas como produtores do conhecimento.

Nota-se que, mesmo sem perceber na época, era essa a visão do professor da disciplina Alexandre D'Agostini Zottis e do coordenador da TV IFSC Paulo Vitor Tavares, ambos do Instituto Federal de Educação Ciência e Tecnologia de Santa Catarina - IFSC, ao assumir o desafio de tornar o aluno elemento ativo no desenvolvimento dos recursos pedagógicos da unidade curricular Radiobiologia do Curso Superior de Tecnologia em Radiologia da instituição.

A seguir, o processo empírico utilizado na produção colaborativa de um conjunto de videoaulas de radiobiologia, é analisado com base na proposta metodológica do Design Thinking para Educadores (IDEO; RIVERDALE, 2013). O papel dos pesquisadores foi buscar pontos de convergência entre ambos.

Identificou-se que o aspecto na educação abordado no caso estudado, conforme a classificação do "Design Thinking para Educadores", foi o Currículo, em que se busca um processo intencional de relacionar o conteúdo aos interesses e desejos dos aprendizes de forma conectada àquilo que fazem fora da escola.

O desafio proposto pelo professor ao Coordenador da TV IFSC e aos alunos da unidade curricular Radiobiologia da $5^{\mathrm{a}}$ Fase, seria transformar em cinco videoaulas os cinco capítulos do manual de radiobiologia produzido por alunos de turmas anteriores do curso. Então, a Definição do Desafio proposta, aqui já reescrita no formato "como podemos" sugerido pelo e-book (IDEO; RIVERDALE, 2013), foi: "Como podemos usar videoaulas no ensino presencial para maximizar o uso do tempo da exposição de conteúdo nas aulas e tornar o aluno parte integrante do processo de produção dos recursos pedagógicos".

Foram compostas cinco equipes de alunos, cada qual com a responsabilidade de estudar um capítulo do manual de radiobiologia e produzir um conteúdo para videoaula tratando dos respectivos temas, sob orientação e apoio da TV IFSC que produziria os vídeos. O resultado esperado era o compartilhamento do conhecimento entre todos os alunos participantes do processo por meio da exibição dos vídeos em sessão única conjunta, sendo que tais vídeos passariam a fazer parte do acervo do curso e incluídos na programação da TV IFSC, destinada ao público em geral.

Pelos registros infere-se que um Plano de Projeto e Cronograma foi definido, contemplando o período de um semestre letivo. Assim, em março foi feita a proposta do Desafio para os alunos e em abril eles fizeram as etapas de Descoberta e Interpretação. No mês de maio ocorreram as prototipagens, com feedbacks, e em junho a Implementação.

Nota-se que foi preciso entender o desafio, o que caracteriza a etapa de "Descoberta". Segundo os dados disponíveis, os três grupos distintos envolvidos no processo reconheceram, inicialmente, a necessidade de identificar algumas restrições e barreiras. A primeira era que os alunos que produziriam o conteúdo de vídeo não possuíam os conhecimentos apropriados de roteirização. Também não era o objetivo da unidade curricular proporcionar essa competência específica. Haveria também resistências da equipe técnico/artística da TV, pois qualquer alteração no gênero ou formato traria uma redução de produtividade. Assim, o Coordenador Geral e a equipe técnico-artística da TV IFSC, em um primeiro momento, consideraram inviável a implementação da solução para o desafio proposto, dentro do padrão de qualidade definido pela TV e do prazo estabelecido pelo proponente. Mas, após conversas entre os envolvidos e refinando o desafio, entendeuse que tal ação seria um importante embrião para a implantação de tecnologias da Educação a Distância no Ensino Presencial, constituindo-se em um avanço na metodologia do ensino requerida pelo aluno no novo mundo das mídias.

Definiu-se que os alunos precisariam saber, como informações iniciais, como funcionam a produção de vídeo e roteirização de vídeo. Precisavam, então, passar pela "Etapa 1 - Inspiração". Assim, nota-se que foram identificadas fontes para coletar inspirações e preparado o trabalho de campo, elaborando-se um cronograma de palestras com o Coordenador da TV IFSC e conversas com a equipe multidisciplinar da TV. Percebese que os alunos puderam mergulhar no contexto do desafio por meio de uma palestra que orientou como transformar o texto de mídia impressa em texto de mídia eletrônica, nesse 
caso, o conteúdo para TV. Na palestra os alunos também conheceram a estrutura do vídeo e exemplos de outros vídeos já produzidos. Assim, conforme recomenda o método, os alunos puderam encontrar inspiração em ambientes semelhantes (outras videoaulas em EAD) e aprender com especialistas e com os usuários (por meio da experiência do coordenador).

Quanto à "Etapa 2 - Interpretação", pelos registros disponíveis, não há confirmação se acabou sendo efetivamente realizada. Observam-se apenas alguns sutis sinais, como quando, durante a palestra, o Coordenador da TV instigou que os alunos fizessem uma analogia entre os processos de produção de videoaulas para a Educação a Distância e de videoaulas requeridas pelo curso presencial, apontando eventuais diferenças no processo.

Dentro da palestra mencionada anteriormente foi iniciado o processo de mobilização dos envolvidos, estimulando a geração de ideias para o desenvolvimento das videoaulas. A partir disto as equipes puderam partir para a "Etapa 3 - Ideação", que foi feita em momento extraclasse. $O$ fato desta etapa ter sido realizada extraclasse implica na falta de registros de como foi desenvolvida. De qualquer forma houve uma perda de oportunidade de aplicá-la da forma indicada pelo método Design Thinking para Educadores, pois os alunos não receberam as instruções que caracterizam um brainstorm.

Com o passo anterior cumprido, percebe-se que houve um refinamento das ideias, já que os alunos ficam responsáveis em transformar as 25 páginas de cada capítulo do manual de radiobiologia em 5 páginas de pré-roteiro de TV (conteúdo para TV). Este choque de realidade foi necessário, pois, o gênero televisivo videoaula define vídeos em torno de 15 minutos de duração com aproximadamente 30 cenas de 30 segundos, divididas igualmente em desenho/grafismo animado, fotografias com locução "em off", participação do (a) professor (a) e participação do (a) apresentador (a), resultando em 7 a 8 cenas para cada forma.

Após a "Ideação", realizada por cada equipe sem acompanhamento, nota-se claramente que houve, neste processo empírico, uma etapa que pode ser relacionada com a "Etapa 4 - Experimentação". Todas as equipes criaram um protótipo, chamado de "préroteiro". Cada equipe apresentou o protótipo ao Coordenador da TV IFSC para obter seu feedback, O coordenador também orienta como os alunos devem indicar nesse texto, possíveis cenas para o roteiro. Todas as equipes fazem nova prototipagem, com indicações de grafismo animado e desenho animado, para serem desenvolvidos pelos profissionais de design da TV IFSC. Estes recursos caracterizam-se como narrativa e storyboard, adequando-se às sugestões de Brown (2010), Vianna et. al. (2012) e Ambrose e Harris (2011). Tendo em mãos os protótipos de pré-roteiro, ilustrações, gráficos e fotos as equipes discutiram com os profissionais de design e roteirista da TV sobre a viabilidade da formulação do roteiro definitivo e animações. Por meio deste ato ocorre novo feedback de especialistas no processo, outro ponto recomendado pelo Design Thinking para Educadores.

Após a "Experimentação", conclui-se pelos registros que a "Etapa 5 - Evolução" também foi aplicada, colocando-se as ideias finalmente em prática. Roteirizados os textos, as equipes de alunos se apresentaram no estúdio da TV IFSC onde realizaram automaquiagem, orientada pela equipe da TV, e participaram no papel de professores, apresentadores e locutores na gravação das videoaulas. Em seguida, foi realizada a edição e finalização pela equipe técnica da TV IFSC e, posteriormente, o material foi compartilhado presencialmente entre os alunos e postado no site da TV para acesso livre pelos alunos do curso e público em geral. Os alunos produziram cinco videoaulas de aproximadamente 15 minutos cada uma, em média.

Ressalva-se que o livro Design Thinking para Educadores não destaca com clareza o momento da Implementação em si, se é o fim da Experimentação ou início da Evolução. Para fins desta análise, a partir da interpretação dos autores, considerou-se a Evolução como etapa de Implementação, relacionando-se com o Design Thinking de Brown (2010).

\section{Considerações finais}


$\mathrm{Na}$ análise, foi possível notar alguns pontos de convergência entre a metodologia do Design Thinking e o processo empírico de produção das videoaulas de radiobiologia, observando-se ações que puderam ser relacionadas às etapas Descoberta, Interpretação, Experimentação e Evolução do método de Design Thinking. Entretanto, as etapas Interpretação e Ideação não foram desenvolvidas de modo formal.

O artigo ao analisar a metodologia Design Thinking, tendo como referência o e-book Design Thinking para Educadores (IDEO; RIVERDALE, 2013), e o caso da produção de videoaulas de radiobiologia, concluiu que é possível aplicar por completo a metodologia do Design Thinking na produção de videoaulas pelos próprios alunos, como método de aprendizagem ativa e colaborativa, e com isso potencializar uma prática educativa baseada na resolução de problemas e na colaboração, incentivando o aluno a vivenciar o próprio processo de construção do conhecimento, vindo ao encontro de uma a nova realidade educacional, conectada, colaborativa e interdisciplinar.

\section{Referências}

AMBROSE, G., \& HARRIS, P. (2011). Design Thinking. Porto Alegre: Bookman.

AYAN, J. (2004). Aha!:10 maneiras de libertar seu espírito criativo e encontrar grandes idéias. 5.ed. São Paulo: Negócio.

BROWN, T. (2010). Design Thinking: uma metodologia poderosa para decretar o fim das velhas idéias. Rio de Janeiro: Elsevier.

IDEO, \& RIVERDALE. (2013). Design Thinking para Educadores. São Paulo: Traduzido por Instituto Educadigital. In: Home: dtparaeducadores. < http://www.dtparaeducadores.org.br >, 14/03/2016.

MARTIN, R. L. (2010). Design de negócios: por que o design thinking se tornará a próxima vantagem competitiva dos negócios e como se beneficiar disso. Rio de Janeiro: Elsevier.

MARTINS FILHO, V., \& GERGE, N. R. (2015). Design thinking, cognição e educação no século XXI. Revista Diálogo Educacional (v.15, n.45: 579 -596). In: Home pucpr. $<$ ttp://www.pucpr.br/dialogo>,30/03/2016.

ROBBINS, S. (2009). Fundamentos do Comportamento Organizacional. (8. ed.). São Paulo: Pearson Prentice Hall.

TAVARES, P. V. (2013). TV e vídeo na educação. (2.ed.). Florianópolis: IFSC.

ZABALA, A. (1998). A Prática educativa: como ensinar. Porto Alegre: ArtMed. 